\title{
Vivienne Harpwood, Medicine, Malpractice and Misapprehensions
}

\author{
Series: Biomedical Law and Ethics Library, Routledge-Cavendish, Oxon, 2007, 224pp. \\ Paperback. 40,10 €. ISBN: 978-0-415-42809-5
}

\section{Adem Koyuncu}

Published online: 5 March 2009

(C) Springer-Verlag 2009

This book examines a very important subject in medicine and medical law that is also relevant from a public health perspective. With respect to its background and purpose, the book's introduction highlights that the public as well as health-care professionals is regularly told that medical malpractice litigation is considerably on the rise and that medicine is more and more practiced in a "compensation culture". Some even assert that "defensive medicine" is the result of doctor's increased litigation exposure. However, there are hardly comprehensive facts providing evidence for these assertions. Therefore, this book wishes to answer some important questions in this regard: What are the facts and trends about malpractice litigation? Is defensive medicine because of litigation risks already a reality? What are the reasons for the increased claims? How can patients seek reassurance that their therapy is safe and, on the other hand, how can doctors practice medicine without the fear of being sued? Particularly, the book aims to present data about medical errors and malpractice claims in the UK and, thus, to provide a "snapshot" of the situation in the UK.

In Chap. 1, the author presents detailed data and information about the number of medical errors and clinical negligence claims and litigation. One main finding here is the fact that currently the available data are "unhelpful" and that there is a need for clear

\footnotetext{
A. Koyuncu $(\bowtie)$

Mayer Brown LLP,

KölnTurm, Im Mediapark 8,

50670 Köln, Germany

e-mail: akoyuncu@mayerbrown.com

URL: www.mayerbrown.com
}

definitions. Obviously, these results are somewhat disappointing. Therefore, they support the recommendation that the statistical evidence in this context must be improved. The author further concludes that a comprehensive system of no-fault compensation for medical injuries in the UK is out of question. This appears to be a convincing conclusion. Chapter 2 analyzes the reasons for the increase in claims. Here, it is found that the increase results from several factors. Chapter 3 discusses whether in the UK there is a compensation culture in health care. Chapter 4 examines the role of the media with respect to health-care litigation, and Chap. 5 asks provocatively whether doctors in the UK are "overpaid, out of control and under-regulated". Finally, Chap. 6 discusses the role of the government and the law in this context. The book concludes with several "tentative recommendations" that are aimed at a better understanding and handling of the underlying issues.

The book's idea and purpose are to put the rather vague and sometimes emotional discussion on medical errors, patient safety, malpractice and litigation on a sound statistical basis and enable a fact-based debate. As such, an evidence-based debate of this subject is overdue (not only in the UK), and the book's approach deserves affirmation. More empirical evidence and (medical and legal) research activities are necessary to further explore and illuminate these topics. Such evidence and research would improve the understanding of malpractice litigation and the causes for medical errors and, in so doing, would also contribute to the public's health. Overall, this book is an interesting and useful resource for readers in the UK and in other countries who are interested in health-care, malpractice and medical law. 